\title{
My kulturBOT 1.0
}

\author{
Frauke Zeller \\ University College London \\ Department of Information Studies \\ Gower Street \\ London WC1E 6BT UK \\ fraukezeller@gmail.com
}

\author{
David Harris Smith \\ McMaster University \\ Department of Communication Studies \\ \& Multimedia \\ 1280 Main Street, Hamilton ON CAN L8S 4L8 \\ dhsmith@mcmaster.ca
}

\begin{abstract}
My kulturBOT 1.0 is a robotic art critic that attends exhibitions and produces tweets and captioned images for social media. kulturBOT indiscriminately takes pictures of the artworks, as well as the venue and the exhibition visitors. It integrates randomness in its movements and its language usage. We use the robot to stress the cognitive agency of artifacts and the inherent vagueness of what Bourdieu described as the 'demarcation line between the world of technical objects and the world of aesthetic objects'. Bourdieu critically reflects on whether this demarcation depends on the intention of the producer of those objects. Rather, he claims, these so-called intentions are themselves a 'product of the social norms and conventions which combine to define the always uncertain and historically changing frontier between simple technical objects and objects d'art' (Bourdieu 1984).
\end{abstract}

Robot. KulturBOT. Cognition. Artifact. Agency.

\section{INTRODUCTION}

My kulturBOT 1.0 is a robotic art critic that attends exhibitions, producing text and captioned images of the artworks, patrons and venue for social media. The kulturBOT project was first conceived as an invited curatorial intervention for an exhibition of new media installation works exploring mediated perception and the modelling of knowledge (Kuball et al. 2013). In the exhibition About the Mind, artists Mischa Kuball, Paulette Philliips, Shaun Gladwell and Wyn Geleynse induce a sense of disequilibrium through some inherent failure or strangeness of the technologies employed in their installations. The works stimulate critical reflexivity through uncertainties of causes and effects, of sense making and truthfulness, and of technical efficacy. The kulturBOT was intended to further develop the cognitive technologies theme of the exhibition, particularly by emphasizing the uncertain engagement of technologies to which we might assign the status of cognitive delegates.

\section{COGNITION AND THE AGENCY OF ARTIFACTS}

Human cognition utilizes both external and reflective internal representations to develop complex thought processes. Theories of distributed cognition (Hutchins 1995), embodied cognition (Anderson 2003), and material and social semiotics (Law 2007, Halliday 1978, Hodge \& Kress 1988), take an ecological approach to the modelling of intelligence in which cognitive systems are distributed or delegated among brains, bodies, tools, artifacts, and the environment. Systems of cognitive delegation afford considerable advantages to human thought processes. External representations provide memory aids: 'The world remembers things for us, just by being there' (Norman 1993); they provide information that can be directly perceived and used without being interpreted and formulated explicitly; they anchor and structure cognitive behaviour and may influence and change the nature of tasks. Artifacts reduce cognitive effort by providing directly perceptible concepts, relations and operations. They can reframe complex synthetic problems as experiential task arrays. Above all, they help to coordinate the translation of abstract problems into experiential spaces and objects (Zhang \& Norman 1994).

According to Clark (1999), we find in human cognitive processes a mixture of embodied strategies and more abstract de-coupled strategies, with external symbolic media often functioning as a kind of bridge between the two:

The external environment, actively structured by us, becomes a source of cognition enhancing 'wideware' - external items (devices, media, notations) that scaffold and complement (but usually do not replicate) biological modes of computation and processing, creating extended cognitive systems whose computational profiles 
are quite different from those of the isolated brain (Clark 1999).

Pinker defines the primary distinction of agents as animacy, that is, living things, having an internal and renewable source of energy that may be directed toward the accomplishment of a goal. But Pinker goes on to address the case of artifacts and tools as a special class of things occupying a middle ground with respect to agency. Things become artifacts when human beings take them up in part of some intentional scheme:

The mixture of mechanics and psychology makes artifacts a strange category. Artifacts can't be defined by their shape or their constitution, only by what they can do and by what someone, somewhere, wants them to do (Pinker 2009).

This dual quality of artifacts, as both physical and intentional things, was described by Heidegger as the difference between the 'present-at-hand'-- the mere physical presence of artifacts-and the 'ready-to-hand'--their apparent readiness of use (Heidegger 1996). Thus, a stone enters into the realm of agential schema when it is used to pound in a stake or to grind corn. Given this understanding of the special status of artifacts as having a contingent form of agency qua human interaction, their inclusion in the formulation of human agency does not risk a leap into magical or essentialist thinking about the power of things. Rather, it is merely to say that the agential properties of artifacts are determined by interpretations of salience and value, as described in Dennett's artifact hermeneutics:

\begin{abstract}
The intention, if any, with which an item was originally introduced determines, at most, what function the author hoped or intended the item to serve, and that hope too is a product of interpretation. We cannot begin to make sense of functional attributions until we abandon the idea that there has to be one, determinate, right answer to the question: What is it for? And if there is no deeper fact that could settle that question, there can be no deeper fact to settle its twin: What does it mean? (Dennett 1990)
\end{abstract}

When seen as contingent agents, the functional attribution of artifacts, their interpretation, is variable and may only be determined for particular cases and times.

McLuhan's aphorism 'the medium is the message' (McLuhan 1964/1994) is specifically addressed to the imbrications of media technologies with cultural forms and psyche. Media in this view extend human agency, servicing some modes of human interaction by technological abstraction and suppressing others. McLuhan is unequivocal in his assessment of the contributions of communication technologies to human agency: 'the artefact is seen to be not neutral or passive, but an active logos or utterance of the human mind or body that transforms the user and his ground' (McLuhan 1978). McLuhan addresses the costs of such material cognition: whenever we identify or recognize something we eliminate most of our rich perceptual field in the process of honing what we 'recognize'. McLuhan saw in the creation of works of art the potential to generate reflexivity about the inherent constraints of cognition:

The artist arrests his cognitions by recognition. $\mathrm{He}$ then reverses the process and embodies in an exterior work the 'drama of apprehension' a process of 'contemplation, purging and domination' (McLuhan 1954)

He speaks of a type of reflexive liberation as a result of cognitive media participation.

Beyond the reflexive 'drama of apprehension,' the delegation of cognitive systems to our media artifacts may also disrupt cognition by subverting perceptual processes, contradicting memory, and refusing recognition. Such cognitive dissonance, however, plays an essential role in human learning and the ongoing development of agency. Often, human agency operates quietly in the background of everyday activity, enabling people to cope with familiar others, tasks and environments. This efficacy appears to rely upon previously validated cognitive patterns or schema (Baumeister 2003, Fiske \& Taylor 1991). Exposure to the anomalous, however, has the effect of drawing attention to the adequacy of our grasp of a given situation and the efficacy of our planning of courses of action. In cognitive terms, the management of discrepancies between, perception, performance, and intentions fuels the adaptive variation of personal agency. Thwarted expectations of efficacy, emotional reactions to disruption, self-reflection, and the revision of concepts, goals, and values, comprise a mechanism of human adaptation that is rooted in the management of cognitive disequilibrium (Bandura 1978).

Delegating the reductive processes of human knowledge production to media technologies allows us to repeat and critically engage in the processes of eliminating possibilities associated with cognition; media interaction allows us to consciously and self-reflexively re-enact processes of information acquisition and definition that reprise and extend the capabilities our own neurobiology. When concepts are prised loose from the grip of actuality, when we impose them onto matter, whether it is mammoth tusk ivory or electronic signals, we enter into a realm of re-cognition that calls forth disequilibrium and reflection. 


\section{CONCEPTUAL DESIGN OF KULTURBOT}

Given the exhibition rubric of technologies of vision, representation, and evaluation, encountered in the exhibition About the Mind, we chose to introduce a robot for its representational capital regarding artificial intelligence and cognition. Mankind's aim to create a machine with which one can communicate and interact is a common leitmotif that stretches from the ancient world to the present. Accompanying the desire to build machines that resemble humankind, has been the fear that these simple machines might one day mutate and overpower mankind, reversing of the master-slave relationship (master-slave is also a basic term in computing architecture). There is also a close connection between the origins of the modern robot and art. Josef Čapek, a Czech artist and painter, is said to the be inventor of the term robot-so claims his brother, Karel Čapek, the author of the play "R.U.R" (Rossum's Universal Robots), in which the term robot was first introduced to a broad public.

Instead of following a Gestalt-oriented approach by using a humanoid robot, we decided to implement a sociable robot (Figure 1). Sociable robots do not necessarily manifest a physical resemblance with human beings; rather, the connection to human beings is achieved through their ability to interact with us. Communicative interaction by usage of language, gestures, and mimicry, is the main aspect of sociable robots.

\section{facebook \& 난 $68^{8}$ Search for people, places and things Q \\ Kultur Bot Timeline $\nabla$ Now $\nabla$ \\ my kulturBOT}

A Research Artwork to Develop and Test a Series of Robotic Art Patrons

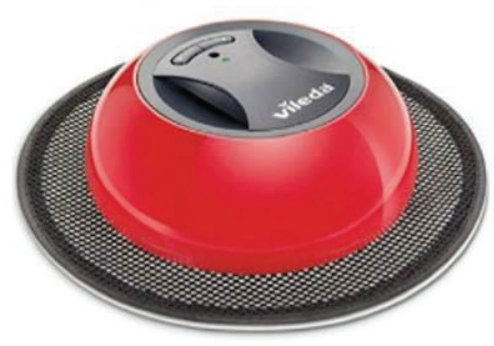

Figure 1: kulturBOT, a social robot

We wanted to use kulturBOT to stress the cognitive agency of artifacts and the inherent uncertainty of what Bourdieu described as the 'demarcation line between the world of technical objects and the world of aesthetic objects' (Bourdieu 1984).
Bourdieu critically reflects on whether this demarcation depends on the 'intention' of the producer of those objects. Rather, he claims, these so-called intentions are themselves a 'product of the social norms and conventions which combine to define the always uncertain and historically changing frontier between simple technical objects and objects d'art' (Bourdieu 1984). Art reviewers act as cognitive-cultural delegates through their exhibition attendance and critical responses to artworks. They act as interpreters of the art pieces, providing a raison d'être for them, and often, some indication of their value. In Bourdieu's terms, they act as catalysts for the conversion of cultural capital to economic capital. We ask, what happens when these important functions of the critic are further delegated to equipment. We also want to question, whether kulturBOT is itself an object of art.

\subsection{A three-fold delegation system}

For our delegate system we chose a threefold set of social norms-or systems that apply social norms and conventions - to delegate the cultural production of robot, art, and cognition. These are manifested by 'algorithm' (relating to robot), 'art exhibition' (relating to the locative aspect of art), and 'language' (relating to the linguistic aspect of cognition).

We implement our robot to 'visit' an exhibition, an act that represents a social concept of where art is to be found-in a gallery. Hence, it replaces the often-difficult question of what art is with the simple solution of a locative definition: Art can be found in an art gallery.

kulturBOT is designed to indiscriminately take pictures of artworks, as well as the venue and the people visiting the exhibition. The kulturBOT is able to cover the exhibition floor-space by utilizing a modified robotic floor sweeper, which simply changes direction upon collision with encountered obstacles. We value randomness for its cognitive potential: A simple, artificial, non-cognitive machine follows a pre-defined path or state-changing system. However, what startles us is when machines apparently do not react in a predictable way. Then they seem to develop their own will, which we tend to associate with intelligence and cognitive abilities.

For the tweeted comments that kulturBOT composites with its images, we chose a random text generator that uses a Markov chain approach. The generator recombines the elements of the Futurist Manifesto (Marinetti 1909) to generate mostly nonsensical phrases of less than 140 characters for tweets and image captioning. The reconstructed strings of text derived from the manifesto retain the tone of passion and revolution of the original but lack its semantic coherence: 
Their own to waste the sea. Then the ideal Mistress the same museums, clutching this marvel. With pride, intoxication and slumber. (text string generated from The Futurist Manifesto, Marinetti 1909).

kulturBOTs nonsensical reproduction of the Futurist Manifesto playfully repositions its technoenthusiasm and revolutionary fervour into conditions of robotic incompetence and failure.

A Markov chain describes a usually discrete stochastic, random process, in which the probabilities of occurrence of various future states depend only on the present state of the system and not on the path by which the present state was achieved. It is important to note that it is 'memoryless', i.e. states at earlier occasions have no additional predictive value. One of Andrey Markov's first examples for the application of a Markov chain was to examine the text of Eugene Onegin in 1913. Today, this concept is used in many areas, such as speech recognition, but especially in the production of random text.

Adapting the concept of the Markov chain to the language of kulturBOT invites reflection upon those interpretations of the work of art as relating to, and becoming meaningful, only regarding its immediate context or surroundings - independent of economic capital and detached from its profound place and function as long-term cultural capital (Bourdieu 1984).

\section{IMPLEMENTATION}

We adopted principles for the construction of kulturBOT stipulating low cost of materials, the use of existing technologies and open source programming environments. We estimate the total cost of parts for the robot to be approximately $\$ 300$ US. For exhibition venues without $\mathrm{Wi}-\mathrm{Fi}$ connectivity an optional mobile LED projection system was added to the robot, nearly doubling the costs for these instances.

A simple collision-sensitive robotic floor sweeper provides the robot's randomized mobility system. The circuitry, imaging and projection systems are mounted to the top of the disc shaped floor sweeper, contained by a stainless steel wire basket. The image and text systems, utilize a tiny adjustable RGB video camera and Arduino electronic modules for $\mathrm{Wi}-\mathrm{Fi}$ connectivity and video/text compositing. The robot has three separate rechargeable power sources to supply the floor sweeper motors, the RGB camera and the Arduino circuit boards. Due to the relatively short mobility cycle (1 hour) afforded by the floor sweeper's power system, we opted to purchase 3 additional floor sweepers and make the entire image and text system transferable among fully charged sweepers. This ensured that kulturBOT would be sufficiently resourced to serve a full day of exhibition viewing.

\section{PERFORMANCE}

The debut performance of kulturBOT occurred at the exhibition opening of About the Mind, Jan 24, 2013, at the McMaster Museum of Art, Hamilton, Canada. A brief artist talk was given by Smith, highlighting kulturBOTs reversal of cherished aspirations for the future of robots, specifically that we humans should live lives of pleasure and delegate the drudgery of our menial tasks to our mechanical inventions. In the case of kulturBOT, it makes much more sense to delegate to it the pleasures of art exhibition attendance and criticism because, frankly, it is not sufficiently intelligent to execute everyday, but nonetheless vital, tasks.

kulturBOT's shortcomings were illustrated by concerns of the museum's administrators that the kulturBOT manifested a type of unwitting surveillance system, potentially posting images of the exhibition's visitors to the Internet. They were especially concerned with the resulting legal implications should kulturBOT randomly capture and post a recognizable image of a child visitor. Concerns were also raised about the public dissemination of photographic reproductions of the museum artworks. What intellectual property infractions were risked by kulturBOT? Further concerns about public safety were raised as the artists and museum staff alike worried about visitors tripping over the randomly moving robot.

The raising of these concerns was somewhat gratifying as they signalled consistency between the robot's reception and its intent to introduce some uncertainty regarding the agency of artifacts. Under what circumstances does a robot become an active agent in an ethical paradigm? What does the robot's potential infractions of ethical norms reveal about the challenges to the current state of development and placement of artificial agents? kulturBOT induces reflection on these issues due in large part to its amateurish assembly of available technologies and its relatively crude imitation of an intelligent system.

To allay the concerns raised by the museum administration, we disabled the robot's social media posts for the duration of the show and opted for a mobile projection display system (Figure 2) and text only tweets (Figure 3). For public safety the robot was only set into random motion in the exhibition under the watchful eye of the artists or museum staff. Exhibition visitors appeared delighted by kulturBOT, following it as it randomly navigated the venue, reading its didactic postings, and observing its images. 


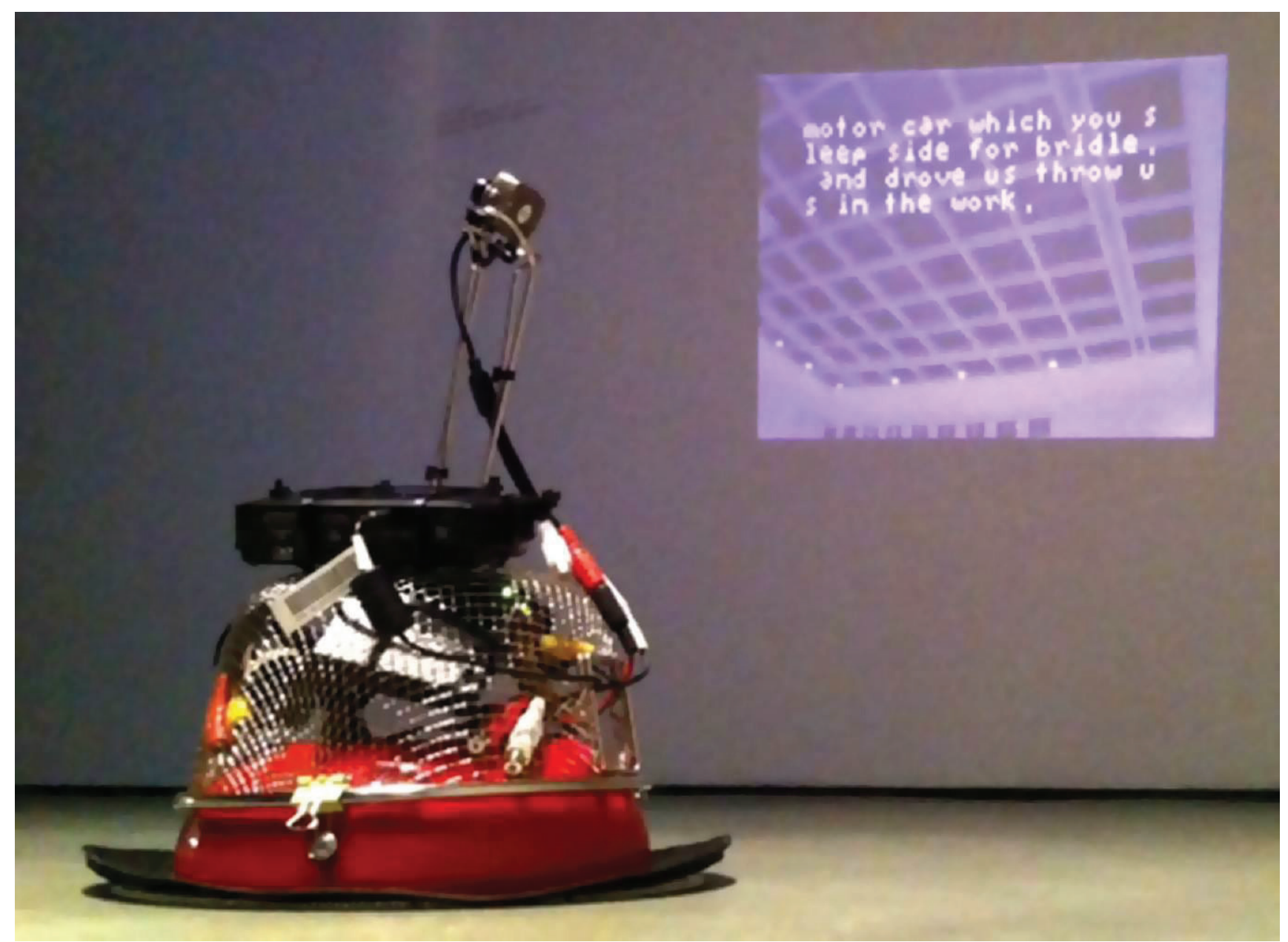

Figure 2: My kulturBOT 1.0

\section{VERSIONING}

A number of improvements have been suggested by the first version (1.0) implementation and performance of kulturBOT. We wish to introduce a greater degree of intelligence to the environmental navigation and image-capture systems. Version 1.0 relies upon the random navigation of the robotic floor sweeper and captures images indiscriminately at timed intervals in its navigation. Thus, it has no ability to distinguish between art and non-art viewpoints in the exhibition environment. More discriminating, yet still randomized imaging points of view may be achieved by linking kulturBOTs navigation to the movements of human visitors to the exhibition venues. Subsequent versions of the robot will utilize the motion capture features of a Kinect camera to identify and follow human visitors in the exhibition space; the orientation and pause durations of human visitors will help to orient kulturBOTs imaging system to points of view that are subject to human attention in the exhibition space and therefore ostensibly art oriented. Linking kulturBOT and human navigation will necessitate employing a controllable mobility system that is responsive to a set object following distance, such as an Arduino compatible two-wheel or four-wheel motorized platform.

Modifications to the image and text captioning system include fitting kulturBOT with a high definition camera and introducing a web crawling algorithm to gather an artist-specific, or themespecific, text corpus for its Markhov chain text processes. Like the visitor-following modification for navigation, kulturBOT can further capitalize upon human capital for its reconstructed critiques. 


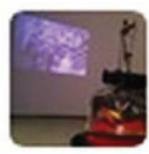

kultur BOT @kulturBOT

offering serpents with its of their eyes.

Expand

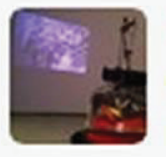

kultur BOT @kulturBOT

27 Mar

our books of the future is no masterpiece that we want to accomplaint prayer

Expand $\&$ Reply 开 Delete $\star$ Favorite $\cdots$ More

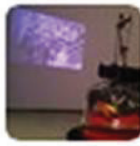

kultur BOT @kulturBOT

27 Mar

The oldest among us are not yet a cruel Queen to demolish

Expand

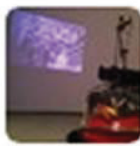

kultur BOT @ kulturBOT

27 Mar

which rage and academies this manuscripts!

Expand

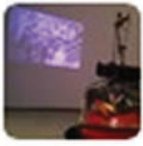

kultur BOT @kulturBOT

from its black fur dappled with and sculptors

Expand

Figure 3: My kulturBOT 1.0 twitter feed

\section{REFERENCES}

Anderson, M. L. (2003) Embodied cognition: a field guide. Artificial Intelligence, 149, pp.91-130.

Baumeister, Z. (2003) The cultural animal: Human nature, meaning, and social life. Oxford University Press, Oxford.

Bourdieu, P. (1984) A social critique of the judgement of taste. Cambridge University Press, Cambridge.

Dennett, D. C. (1990) The interpretation of texts, people, and other artifacts. Philosophy and Phenomenological Research, 50. pp.177-194.

Fiske, S. T. and Taylor, S. E. (1991) Social Cognition (2nd ed.). McGraw-Hill, New York.

Halliday, M. A. K. (1978) Language as social semiotic: The social interpretation of language and meaning. University Park Press, Maryland.

Hodge, R., and G. Kress. (1988) Social Semiotics. Polity, Cambridge.
Hutchins, E. (1995) Cognition in the wild. MIT Press, Cambridge.

Law, J. (2007) Actor Network Theory and Material Semiotics.

http://heterogeneities.net/publications/Law-

ANTandMaterialSemiotics.pdf (retrieved 25 April 2009).

Marinetti, F.T. (1909) Futurist Manifesto. http://www. italianfuturism.org/foundingmanifesto/ (retrieved 25 April 2012).

Norman, D. A., 1993. Things that make us smart: Defending human attributes in the age of the machine. Perseus Books, Cambridge.

Zhang, J. and Norman, D. A. (1994) Representations in distributed cognitive tasks. Cognitive Science, 18, pp.87-122. 